\title{
Endoscopic Drainage of Walled off Necrosis - A "Multidisciplinary Affair"?
}

\author{
Zaheer Nabi ${ }^{1}$, Jagdeesh R Singh ${ }^{2}$, Sundeep Lakhtakia ${ }^{1}$ and Nageshwar Reddy D $^{3}$ \\ ${ }^{1}$ Consultant gastroenterologist, Asian institute of Gastroenterology, India \\ ${ }^{2}$ Consultant radiologist, Asian institute of Gastroenterology, India \\ ${ }^{3}$ Chairman and Chief Gastroenterologist, Asian institute of Gastroenterology, India
}

Submission: September 15, 2017; Published: November 21, 2017

"Corresponding author: Zaheer Nabi MD, Asian Institute of Gastroenterology, 6-3-661, Somajiguda, Hyderabad - 500 082, India, Tel: +91-40-2337 8888; Email: zaheernabi1978@gmail.com

\section{Case Report}

A 12-year old boy was hospitalized with history of acute necrotizing pancreatitis ( 7 weeks). Evaluation revealed large walled off necrosis (WON). The child had persistent symptoms in form of pain abdomen and intolerance to oral diet. Endoscopic ultrasound (EUS) guided drainage was performed using a lumen apposing metal stent (LAMS). The drainage procedure was accomplished without any immediate untoward consequences. There was significant improvement in clinical symptoms as well as the size of WON on day
3 of drainage. However, the child had a large bout of hematemesis on day 4 of drainage. Gastroscopy revealed LAMS in situ and partially occludedby a large clot arising from the cyst cavity (Figure 1a \& 1b). Urgent angiography was performed via right femoral artery, which revealed leak from superior pancreaticoduodenal artery (Figure 1c \& 1d). The leak of contrast was localized along the lateral edge of LAMS, near farther end. Coil embolization was done following which there was no extravasation of contrast from the artery involved (Figure 2a \& 2b).

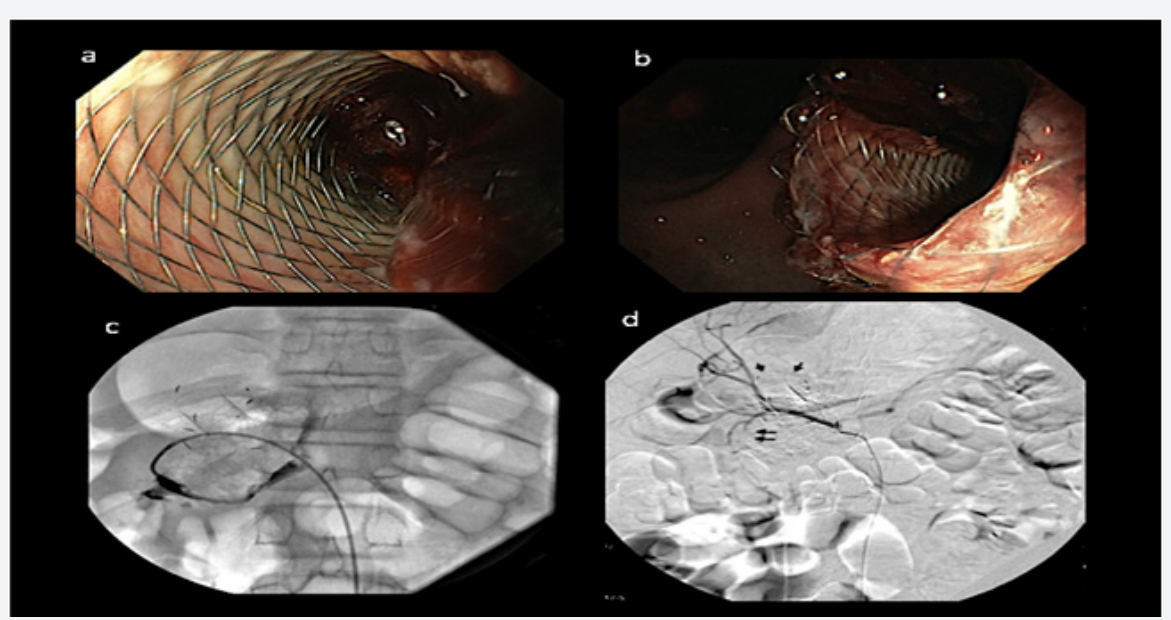

Figure 1: Endoscopic image of lumen apposing metal stent (LAMS).

a. Endoscopic view from within the LAMS (note the large clot arising from within the cyst cavity).

b. Endoscopic view of LAMS from outside.

c. Angiogram revealing leak of contrast from superior pancreaticoduodenal artery (arrows). Note the flow of contrast towards cyst cavity.

d. Digital subtraction image showing LAMS (short arrows) and leak site localized along the edge of LAMS (long arrows). 


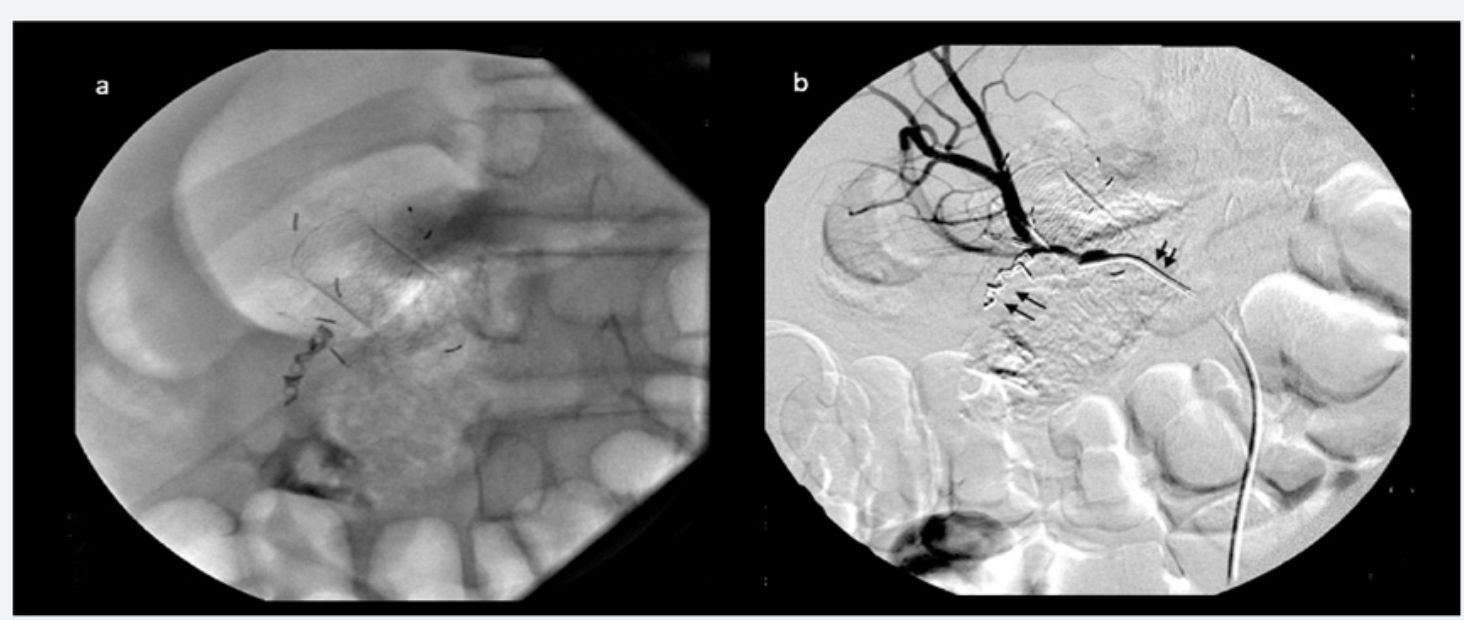

Figure 2: Angiogram obtained after coil embolization.

a. Angiogram after placement of coils (long arrows) in the culprit vessel. Note the extra-vasated contrast in the cyst cavity (short arrows).

b. Digital subtraction image showing confirming absence of leak site after coil embolization.

Intra-procedural bleeding can be largely evaded by EUS guidance which avoids intervening vessels [1,2]. In contrast, it may not be possible to prevent delayed bleeding i.e. 3-5 weeks after endoscopic drainage. The management of WON is therefore, a multidisciplinary affair involving interventional radiologists and surgeons [3].

\section{References}

1. Nabi Z, Talukdar R, Reddy DN (2017) Endoscopic Management of Pancreatic Fluid Collections in Children. Gut Liver 11(4): 474-480.
2. Varadarajulu S, Christein JD, Tamhane A, Drelichman ER, Wilcox CM (2008) Prospective randomized trial comparing EUS and EGD for transmural drainage of pancreatic pseudocysts (with videos). Gastrointest Endosc 68(6): 1102-1111.

3. Nabi Z, Basha J, Reddy DN (2017) Endoscopic management of pancreatic fluid collections-revisited. World J Gastroenterol 23(15): 2660-2672. 